\title{
Development of a Measure of the Motives Underlying the Selection of Food: the Food Choice Questionnaire
}

\author{
ANDREW STEPTOE and TESSA M. POLLARD \\ Department of Psychology, St George's Hospital Medical School, London
}

\author{
J ANE WARDLE \\ Imperial Cancer Research Fund Health Behaviour Unit, Institute of \\ Psychiatry, London
}

\begin{abstract}
A number of factors are thought to influence people's dietary choices, including health, cost, convenience and taste, but there are no measures that address healthrelated and non-health-related factors in a systematic fashion. This paper describes the development of a multidimensional measure of motives related to food choice. The F ood Choice Questionnaire (FCQ) was developed through factor analysis of responses from a sample of 358 adults ranging in age from 18 to 87 years. $\mathrm{N}$ ine factors emerged, and were labelled health, mood, convenience, sensory appeal, natural content, price, weight control, familiarity and ethical concern. The questionnaire structure was verified using confirmatory factor analysis in a second sample $(n=358)$, and test-retest reliability over a 2- to 3-week period was satisfactory. Convergent validity was investigated by testing associations between FCQ scales and measures of dietary restraint, eating style, the value of health, health locus of control and personality factors. Differences in motives for food choice associated with sex, age and income were found. The potential uses of this measure in health psychology and other areas are discussed.
\end{abstract}

(c) 1995 A cademic Press Limited

\section{INTRODUCTION}

Concern about food choices that may have adverse effects on health is widespread in the developed world, and is embodied in documents such as $\mathrm{H}$ ealthy People 2000 (1992) and The $\mathrm{H}$ ealth of the $\mathrm{N}$ ation (1992). R ecommendations to restrict salt and fat intake and increase complex carbohydrate and fibre consumption are central tenets in public health nutrition guidelines (Cannon, 1992). N evertheless, fat consumption remains high in the western world, and is increasing in countries undergoing industrial development (L ands et al., 1990; Trichopoulou \& Efstathiadis, 1989).

Effective modification of dietary patterns depends on an understanding of the factors governing food choice. Recent years have witnessed growing interest in studying the attitudes and beliefs associated with healthy eating. M easures of

This research was supported by G rant L 209252013 from the E conomic and Social R esearch Council, U .K. We are grateful to Emma Winstanley for her assistance in data collection.

A ddress correspondence to: D r A. Steptoe, D epartment of Psychology, St G eorge's H ospital M edical School, Cranmer Terrace, London SW 17 ORE, U.K. 
attitudes relevant to theoretical frameworks such as the health belief model and the transtheoretical model of change have been developed (K ristal et al., 1990; Smith \& O wen, 1992; Trenkner et al., 1990). F or example, G lanz et al. (1993) have described measures of psychosocial factors influencing fat and fibre consumption, including items related to beliefs in the links between diet and disease, perceived benefits and barriers to behaviour change, social support, social norms, motivation and selfefficacy. This work holds the promise of leading to improved dietary modification programmes (M cCann et al., 1990). However, health is clearly not the only factor people take into account when choosing their food, and a focus on health may lead to exclusive emphasis on a set of motives that are of limited significance for many people. It is therefore important to explore the role of other influences on food choice.

It has long been recognized that food availability and cultural factors are dominant in food selection. Cultural influences lead to differences in the habitual consumption of certain foods and in traditions of preparation, and in certain cases can lead to restrictions such as exclusion of meat and milk from the diet ( $\mathrm{Lau}$, $\mathrm{K}$ rondl \& Coleman, 1984). F ood is a focus of social interaction, and the consumption of "prestige" foods may become an index of social status (Sanjur, 1982). The system of provision, including food production and manufacture, marketing, delivery and sale, has been shown to have a major impact on what people eat ( $F$ ine $\&$ Leopold, 1993). A t the individual level, taste or sensory appeal, likes and dislikes, and sheer habit are all relevant ( $K$ rondl \& L au, 1982; R ozin, 1984; Parraga, 1990). Taste may be particularly important in selection of high fat diets, since fats are responsible for the texture and aroma of many foods (D renowski, 1992). On the other hand, "healthy" diets may be consumed for non-health reasons such as concern about appearance (Cockerham, K unz \& Lueschen, 1988). Weight control is a major determinant of food choice for individuals concerned about their body weight. The growth in environmental awareness over the past two decades has led to concerns about the use of natural ingredients and packaging that may have an impact on purchasing decisions. There is also evidence that stress and negative emotions may influence food selection and consumption (M cCann, Warnick \& K nopp, 1990; Wardle, 1987a). All these factors indicate that health is only one of many considerations relevant to food choice. $M$ ore effective implementation of health promotion strategies may depend on the recognition of the status of health in comparison with other motives in the selection of food.

\section{M ultidimensional M easures of Food Choice}

Efforts to develop multidimensional measures of factors related to food choice at the individual level, including both health and non-health motives, have been limited. Repertory grid approaches have been attempted, but these are time-consuming and patterns tend not to be stable across individuals (B ell et al., 1981; Tuorila $\&$ Pangborn, 1988). Ratings of different foods on dimensions such as pleasure, health, tradition, convenience, familiarity, prestige and price were described by $L$ au et al. (1984) and by R appaport and coworkers (1992), but in neither case was a formal set of measures developed. A more systematic method was developed by $M$ ichela and Contento (1986) in a study of 5- to 13-year-old children. A series of foods were rated on a number of dimensions including healthfulness, taste, convenience and social influence. Substantial variations in the intraindividual correlations between 
evaluative ratings and consumption of these same foods were found, and clusters of subjects characterized by different motivational patterns were identified.

This approach has been extended by Wardle (1993) who included ratings of liking (taste) and health for a range of foods in a study of mothers and their adult children. Two indices were constructed for each individual based on the correlation between liking ratings and consumption frequency (taste index) and between "healthiness" ratings and consumption frequency (health index). The taste index was consistently higher than the health index, although there was a good deal of variation across individuals in both. The health index was higher in older women than either their adult sons or daughters. The advantage of this method is that it circumvents the need for subjects to give introspective reports on their motives, but it has the drawback of being time-consuming and inappropriate for large-scale research.

$M$ ore conventional questionnaire methods have been developed for the investigation of eating disorders, including the restraint scale (Polivy, Herman \& Warsh, 1978), the Three F actor Eating Questionnaire (Stunkard \& M essick, 1985) and the Dutch Eating Behaviour Questionnaire (Van Strein et al., 1986). However, these measures are more concerned with cognitive restraints on food intake and the circumstances surrounding excessive consumption than with the factors influencing food choice. A $\mathrm{n}$ 18-item R easons for Eating Scale was devised by $\mathrm{H}$ armatz and K err (1981), and responses from 110 students were factor analysed by Williams, Spence and Edelman (1987). Six factors emerged, highlighting the importance of affect on eating, as well as sensory appeal, habit and pleasure in food preparation. However, the questionnaire was developed for the investigation of obesity, and is limited in scope.

The N utrition A ttitudes Survey, a measure of attitudes relevant to low-fat diets, has been described by $\mathrm{H}$ ollis et al. (1986). F our factors emerged from the survey of 357 adult volunteers, and included "helpless and unhealthy", "food exploration", "meat preference" and "health consciousness". The helpless and unhealthy and meat preference factors were both associated with high meat consumption and with elevated low density lipoprotein concentration in the blood, while the health consciousness factor was associated with lower meat consumption. The helpless and unhealthy factor identified by $\mathrm{H}$ ollis et al. combines items about convenience (e.g. "many days, because I' $m$ in a hurry, I eat whatever is handy"), mood and affect ("I eat more when I feel down"), and low self-efficacy ("when it comes to food, I have no will-power"). The health consciousness factor predominantly indexes willingness to change ("to avoid heart disease, I would be willing to alter my eating habits") rather than concerns about health that currently govern food choice. The general applicability of the measure is limited by the omission of items concerning sensory appeal and cost.

Evaluation of this literature suggests that the development of a multidimensional questionnaire to assess the perceived importance of different factors in food choice might be valuable both in the investigation of food consumption and in health and consumer psychology more broadly. The assessment of different factors within the same measure allows direct comparisons to be made about the relative importance of dimensions such as health, price, sensory appeal and convenience. We hypothesized that several distinct factors associated with food choice would be identified as well as the four listed above, since concern with weight control, the degree of familiarity of the food, and mood have all been cited as relevant in previous studies. In this paper, we describe the development of the measure and identification of dimensions 
through factor analysis, its validation in an independent sample using confirmatory factor analysis, test-retest reliability over a 2- to 3-week interval, and associations with other variables such as sex, age, income, eating style, social desirability biases and health values. The relationship between responses to the questionnaire and patterns of food consumption is a separate issue related to the applications rather than validation of the instrument, so will be presented elsewhere.

\section{STUDY 1}

In Study 1, a preliminary food choice questionnaire of 68 items was generated through consideration of existing literature and discussion with nutritionists and health psychologists. I tems covered various motives that have been identified in other research, including commonly recognized factors such as health, sensory appeal, convenience of purchase and cost, together with areas of potential significance such as environmental concerns and the extent to which food conforms to the preferences of family and peer group. M easures of dietary restraint, emotional eating, social desirability response biases, and health value were also administered, and associations with food choice factors evaluated as evidence of convergent validity. D emographic characteristics including marital status, occupation, education, income and eating habits (vegetarian etc.) were also collected.

\section{ETHOD}

\section{Subjects}

Q uestionnaires were posted to 105 university students, 90 employees of a university library, and 635 people selected at random from the electoral register of a L ondon borough; $68 \%$ of the students, $64 \%$ of the library employees and $40 \%$ of the $L$ ondon residents returned completed questionnaires, giving a sample of 358. The sample included 220 women and 138 men, and ranged in age from 18-87 (mean 34.1, SD 15.2). The body mass index of participants averaged 23.7 (SD 3.2). N o respondents stated that they suffered from a chronic disease requiring a special diet; $40.9 \%$ were married or living with a partner, $49.3 \%$ were single, and $9.8 \%$ were separated or widowed; 64 subjects (17.9\%) reported that children lived at home with them; $61 \%$ of the sample were in full or part-time employment, $23.2 \%$ were students, $8.9 \%$ were unemployed or homemakers and $6.7 \%$ were retired. In terms of education, $10.8 \%$ had no formal qualifications while a further $15.6 \%$ left school having completed the General Certificate of Secondary Education (GCSE, equivalent to tenth grade); $38.4 \%$ had completed high school with A level qualifications, and $35.2 \%$ had university degrees. The reported annual income of subjects was distributed as follows: $<£ 5000$, $34.5 \%$ (mainly students); $f 5000-£ 10000,10 \cdot 7 \%$; $f 10000-£ 15000, \quad 18 \cdot 1 \%$; $f 15000-£ 20000,12 \cdot 4 \%$; $£ 20000-£ 30000,13 \cdot 6 \%$; >£30 000, $10 \cdot 7 \%$.

\section{$M$ aterials}

P reliminary food choice questionnaire ( FCQ)

The preliminary questionnaire was designed to assess a wide range of considerations that might be taken into account by individuals when choosing what to 
eat (see Table 1). Subjects were asked to endorse the statement "It is important to me that the food I eat on a typical day ..." for each of the 68 items by choosing between four responses: not at all important, a little important, moderately important and very important, scored 1 to 4.

Dietary restraint and eating style

E ating style was assessed with the D utch E ating Behaviour Questionnaire (DEBQ) (Van Strein et al., 1986). This measure consists of 33 items concerning eating habits that assess three factors: restrained eating, indexing restraint in the consumption of food and dieting behaviour; emotional eating, where items concern eating when upset or in negative moods; and external eating, concerned with disinhibition and eating in response to the sight or smell of food. Scores on each scale could range from 1-5, with higher scores indicating greater restraint, sensitivity to emotional conditions and sensitivity to external cues. The scale has advantages over other similar measures (Wardle, 1986), and has been shown to be robust in the U.K. population (Wardle, 1987b). The internal consistency (Cronbach $\alpha$ ) scores in the present sample were $0.92,0.95$ and 0.77 for the restraint, emotional eating and external scales respectively.

Value of health

The value that individuals place on good health was assessed using the $\mathrm{H}$ ealth as a Value scale developed by Lau, Hartman and Ware (1986). This four-item questionnaire consists of statements such as "If you don't have your health, you don't have anything", and responses were scored on a six-point scale where $1=$ strongly disagree to $6=$ strongly agree. $R$ atings across the four items were averaged to produce scores in the range 1-6. The $\mathrm{H}$ ealth as a Value scale is a reliable measure that has been widely used in health research.

Social desirability

Social desirability biases were assessed using the ten-item reduction of the M arlowe Crowne social desirability scale developed by Strahan and G erbasi (1972), in which higher scores reflect greater tendencies towards producing socially favourable responses.

\section{R ESULTS}

\section{Scale Construction and Factor A nalysis}

The 68 items of the FCQ were factor analysed with varimax rotation. Various solutions were considered, but the structure that appeared best to combine ecological sense with parsimony involved nine factors that together accounted for $49.5 \%$ of the variance, with Eigen values ranging from $12 \cdot 4$ to $1 \cdot 72$. I tems with a severely skewed distribution and those which did not load clearly on a single factor were discarded. In order to develop a relatively short questionnaire, a maximum of six was set on the number of items included on each scale, and the highest loading items were selected. This procedure resulted in the retention of 36 items.

Table 1 summarizes the factor analysis performed on the 36 item FCQ. The nine factors accounted for $65 \cdot 2 \%$ of the variance. F actor 1 consists of six health-related statements and is therefore labelled health (Cronbach $\alpha=0.87$ ). F actor 2 is composed 
TABLE 1

F ood Choice Q uestionnaire- items and factor loadings

It is important to me that the food I eat on a typical day:

L oading

F actor $1-\mathrm{H}$ ealth

22. Contains a lot of vitamins and minerals $\quad 0.77$

29. K eeps me healthy $\quad 0.75$

10. Is nutritious $\quad 0.75$

$\begin{array}{ll}27 . & \text { Is high in protein } \\ 30 . & 0.72\end{array}$

30. Is good for my skin/teeth/hair/nails etc $\quad 0.68$

$\begin{array}{ll}9 . & \text { Is high in fibre and roughage } \\ & 0.66\end{array}$

F actor 2-M ood

16. H elps me cope with stress $\quad 0.79$

34. H elps me to cope with life $\quad 0.79$

26. Helps me relax $\quad 0.78$

24. K eeps me awake/alert $\quad 0.60$

13. Cheers me up $\quad 0.60$

31. M akes me feel good $\quad 0.57$

F actor 3-Convenience

$\begin{array}{ll}1 . & \text { Is easy to prepare } \\ & 0.82\end{array}$

15. Can be cooked very simply $\quad 0.81$

28. Takes no time to prepare $\quad 0.76$

35. Can be bought in shops close to where I live or work $\quad 0.65$

$\begin{array}{ll}11 . & \text { Is easily available in shops and supermarkets } \\ \end{array}$

Factor 4-Sensory A ppeal

$\begin{array}{ll}\text { 14. Smells nice } & 0.80\end{array}$

25. Looks nice $\quad 0.72$

$\begin{array}{ll}\text { 18. } \mathrm{H} \text { as a pleasant texture } & 0.70\end{array}$

4. Tastes good 0.53

F actor $5-\mathrm{N}$ atural Content

2. Contains no additives $\quad 0.81$

$\begin{array}{ll}\text { 5. Contains natural ingredients } & 0.72\end{array}$

23. Contains no artificial ingredients $\quad 0.71$

F actor 6-Price

$\begin{array}{ll}6 . & \text { Is not expensive } \\ 36.87\end{array}$

36. Is cheap $\quad 0.87$

12. Is good value for money $\quad 0.76$

Factor 7-Weight Control
3. Is low in calories

$\begin{array}{ll}\text { 3. Is low in calories } & 0.87 \\ \text { 17. Helps me control my weight } & 0.79\end{array}$

$\begin{array}{ll}\text { 7. Is low in fat } & 0.74\end{array}$

Factor 8-Familiarity

33. Is what I usually eat $\quad 0.79$

$\begin{array}{ll}8 . \text { Is familiar } & 0.79\end{array}$

21. Is like the food I ate when I was a child $\quad 0.66$

F actor 9-Ethical Concern

20. Comes from countries I approve of politically $\quad 0.87$

$\begin{array}{ll}32 . & \mathrm{H} \text { as the country of origin clearly marked } \\ & 0.79\end{array}$

$\begin{array}{ll}\text { 19. Is packaged in an environmentally friendly way } & 0.43\end{array}$

Item numbers refer to the order in which statements were presented in the final 36 item F ood Choice Questionnaire.

The full factor analysis matrix is available on request from the authors. 
TABLE 2

Intercorrelations $(\times 100)$ between Food Choice Q uestionnaire factors

\begin{tabular}{|c|c|c|c|c|c|c|c|c|}
\hline & H ealth & M ood & Convenience & $\begin{array}{l}\text { Sensory } \\
\text { appeal }\end{array}$ & $\begin{array}{l}\mathrm{N} \text { atural } \\
\text { content }\end{array}$ & Price & $\begin{array}{l}\text { Weight } \\
\text { control }\end{array}$ & Familiarity \\
\hline M ood & $34 *$ & & & & & & & \\
\hline $\begin{array}{l}\text { Convenience } \\
\text { Sensory }\end{array}$ & 14 & $27 *$ & & & & & & \\
\hline $\begin{array}{l}\text { appeal } \\
\mathrm{N} \text { atural }\end{array}$ & $19 *$ & $32 *$ & 5 & & & & & \\
\hline content & $59 *$ & $28 *$ & -5 & $22 *$ & & & & \\
\hline $\begin{array}{l}\text { Price } \\
\text { Weight }\end{array}$ & $20 *$ & 14 & $32 *$ & 4 & 9 & & & \\
\hline control & $38 *$ & $21 *$ & 7 & 2 & $31^{*}$ & 14 & & \\
\hline $\begin{array}{l}\text { F amiliarity } \\
\text { E thical }\end{array}$ & 9 & $34 *$ & $29 *$ & 13 & 8 & 13 & -5 & \\
\hline concern & $37 *$ & $25^{*}$ & 12 & 13 & $39 *$ & $22 *$ & 9 & 10 \\
\hline
\end{tabular}

${ }^{*} p<0 \cdot 001$

of six items concerning stress, coping and mood, and is consequently labelled mood $(\alpha=0.83)$. F actor 3 has fiveitems and concerns ease of food purchase and preparation, and is therefore considered to be a convenience factor $(\alpha=0.81)$. F actor 4 consists of four statements related to appearance, smell and taste, and can be regarded as indexing sensory appeal $(\alpha=0 \cdot 70)$. F actor 5 includes three items related to the use of additives and natural ingredients, and is labelled natural content $(\alpha=0.84)$. F actor 6 has three items associated with cost of food, and indexes price as a motive in food selection $(\alpha=0.82)$. Factor 7 consists of three items related to consumption of low calorie food and is labelled weight control $(\alpha=0 \cdot 79)$. F actor 8 is also composed of three items, and these are associated with familiarity $(\alpha=0 \cdot 70)$. F actor 9 has three items concerned with environmental and political considerations and is labelled ethical concern $(\alpha=0 \cdot 70)$.

Scores on each scalewere computed by averaging unweighted ratings for individual items, so could range from a minimum of 1 to a maximum of 4 . The intercorrelations between the scales of the FCQ are shown in Table 2. A number of significant associations were observed. The most prominent was between food choice motives related to health and to natural content $(r=0.59)$. There were also moderate correlations between health and mood, ethical concern and weight control, between mood, sensory appeal and familiarity, and between convenience and price. H owever, none of these remaining correlations implied more than $14 \%$ shared variance.

The associations between the FCQ and other measures such as the DEBQ and $\mathrm{H}$ ealth as a Value questionnaire are discussed later in the section on convergent validity.

\section{STUDY 2}

Study 2 was designed to assess the replicability of the nine-factor FCQ in a new community sample, and test the reproducibility scores over a 2- to 3-week period. In addition, the associations between the $\mathrm{FCQ}$ and two pertinent personality traits, 
neuroticism and openness to experience, were evaluated. The internal subscale of the M ultidimensional Health Locus of Control (M HLOC), Health as a Value and the social desirability measure were also administered.

M ETHOD

Subjects

A postal survey was carried out with 400 students and 641 London residents. R eplies were received from 135 (34.0\%) students and 223 (34.8\%) residents, giving a sample of 358. The mean age was 30.5 (SD 14.3) with a range of 17-89 years, and the sample included 184 women and 174 men. The mean body mass index was $23.8 \mathrm{~kg} / \mathrm{m}^{-2}$ (SD 3.5), and no participants reported suffering from a chronic disease involving a special diet. The proportion of married subjects was $66 \cdot 3 \%$, while $29 \cdot 2 \%$ were single and $4.5 \%$ were divorced or widowed. The number of respondents with children living at home was $54(15 \cdot 1 \%)$, a similar proportion to that found in Study 1. The proportion of respondents in full or part-time employment was $44.7 \%$, $40.9 \%$ were students, $7 \%$ were unemployed or homemakers and $6.4 \%$ were retired. Educationally, $10.9 \%$ had no formal qualifications, and $12.3 \%$ had achieved GCSE level. The proportion with A levels (high school completion) was $51.0 \%$ while $25 \cdot 8 \%$ had degrees. In terms of annual income distribution, 50.1\% reported an income of less than $f 5000$; $f 5000-£ 10000,7 \cdot 8 \%$; $£ 10000-£ 15000,11.6 \%$; $£ 15000-£ 20000$, $9.9 \% ; £ 20000-£ 30000,10 \cdot 4 \% ;>£ 30000,10 \cdot 1 \%$.

Two weeks after receipt of the questionnaires, a repeat questionnaire (consisting of the FCQ and a food frequency questionnaire) was sent out. The food frequency data are not described in this report. A total of $245(68.4 \%)$ of subjects returned the second questionnaire within a 48-day period. The average number of days between completion of the two questionnaires was $19 \cdot 7$ (SD 5.2).

\section{M aterials}

In addition to the 36-item FCQ, health as a value and social desirability measures described earlier, additional questionnaires were as follows.

\section{Personality}

Two factors from the NEO Five-F actor Inventory (F orm S) were administered (C osta \& M cC rae, 1991). We selected neuroticism as potentially relevant in the light of its relationship with health risk, stress and coping, and the openness to experience factor as potentially relevant to willingness to eat a wide range of foods. Each factor consists of twelve items rated on a five-point scale, and scores could range from 0 to 48 with higher ratings representing greater neuroticism and openness to experience. The reliability of the measure has been extensively evaluated, and it has been used widely in personality research, counselling and health psychology (Costa \& M cCrae, 1992).

\section{L ocus of control}

Respondents' beliefs in their ability to influence their own health status were assessed with the internal health locus of control scale (F orm B) from the M HLOC 
(Wallston, Wallston \& D eVellis, 1978). This scale consists of six items (e.g. "I am directly responsible for my health"), and subjects responded on a six-item scale ranging from $1=$ strongly disagree to $6=$ strongly agree. $R$ atings were averaged to produce a score in the range 1-6, with higher scores reflecting greater perceptions of internal control over health.

\section{Data A nalysis}

Confirmatory factor analysis was carried out with structural equation modelling using the EQS program (Bentler, 1989), with the generalized least squares (GLS) normal theory estimation method. Because $\chi^{2}$ fit indices are sensitive to sample size, models with good fit may show large $\chi^{2}$ values when the sample size is large. We therefore used the ratio of chi-squared to degrees of freedom as suggested by $M$ arsh, Balla and M CD onald (1988), with values under five indicating reasonable fit. In addition, the non-normed fit index (N N FI, Bentler \& Bonett, 1980) and the comparative fit index (CFI, Bentler, 1990) were used to evaluate model fit.

\section{RESULTS}

\section{Confirmatory F actor A nalysis}

The simple nine-factor model in which each item of the FCQ loaded on a single factor provided a good fit for the data collected in Study $2(n=358), \chi^{2}=997, d f=$ 594, $p<0.001 ; \mathrm{NNFI}=0.991 ; \mathrm{CFI}=0.991$ (Fig. 1). All parameters estimates were significant at $p<0.001$. A llowing factors to intercorrelate gave a modest improvement in fit. These analyses indicate that the FCQ factor structure identified in Table 1 was confirmed in the independent Study 2 sample.

\section{Test- R etest R eliability and Internal Consistency}

It can be seen that all correlations between scores at the two administrations of each FCQ scale were $>0.70$ (Table 3 ), suggesting that the reliability of the scales is acceptable. The mean scores on the two occasions were significantly different for two factors, health and mood, $t(245)=2.42$ and 2.98 respectively, $p s<0.025$. In each case, average ratings were slightly reduced on the second occasion. Intercorrelations between the factors were similar to those detailed for Study 1 in Table 2. The internal consistency of the F CQ factors was high, with Cronbach a scores as follows: health $=$ $0.81, \operatorname{mood}=0.83$, convenience $=0.84$, sensory appeal $=0.72$, natural content $=0.86$, price $=0.83$, weight control $=0 \cdot 85$, familiarity $=0 \cdot 72$, ethical concern $=0 \cdot 74$.

\section{A ssociations with Sex, A ge and Income}

A comparison was made of body mass index and of scores on the FCQ scales in Studies 1 and 2, including sex as a factor and covarying for age. No significant differences between studies were observed. Consequently, the samples from Studies 1 and 2 were combined for investigating differences by sex, age and income.

The multivariate analysis of variance comparing men and women with age as a covariate showed an overall effect of sex, $F(9,651)=14 \cdot 3, p<0 \cdot 001$ (Table 4). Separate 

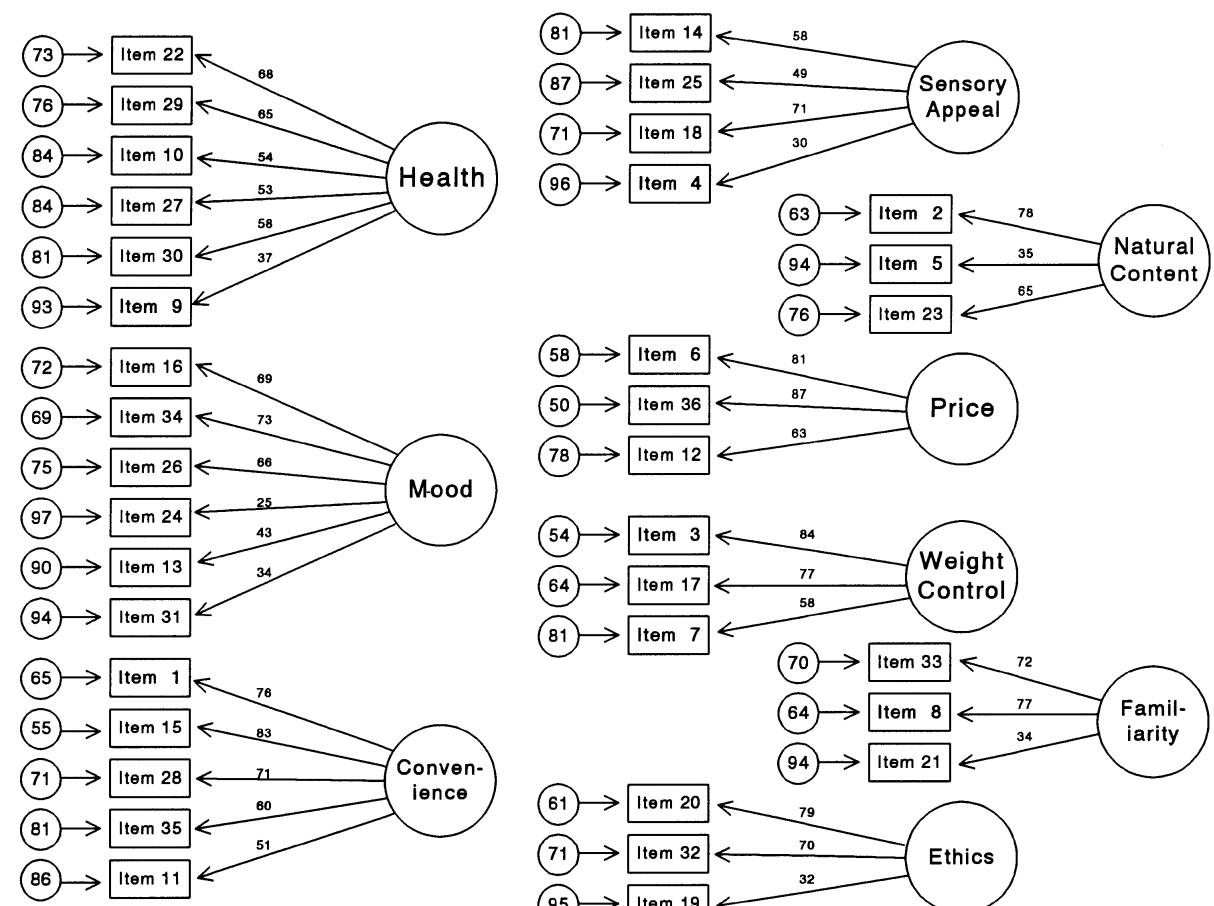

(81) $\rightarrow$ Item 7

(70) $\rightarrow \operatorname{ttem} 33<\quad 72$

(61) $\rightarrow$ Item 20
(71) $\rightarrow$ Item 32
95 $\rightarrow$ Item 19

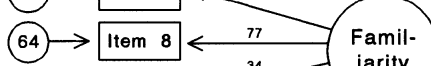

(94) $\rightarrow$ Item 21 iarity<smiles>[3H]</smiles>

79 Ethics (95) $\rightarrow$ Item $19 \longleftarrow 32$

F IGURE 1. Summary of confirmatory factor analysis model for the Food Choice Questionnaire. R ectangles represent the measured variables, with item numbers corresponding to items in the FCQ (see Table 1). Large circles are latent constructs (factors) and small circles are residual variances $(\times 100)$. Parameter estimates are standardized $(\times 100)$.

TABLE 3

Test-retest reliability of the F ood Choice Q uestionnaire $(n=245)$

\begin{tabular}{|c|c|c|c|c|c|}
\hline \multirow[t]{2}{*}{ Scale } & \multicolumn{2}{|c|}{ Time 1} & \multicolumn{2}{|c|}{ Time 2} & \multirow[b]{2}{*}{$\begin{array}{c}\text { Correlation } \\
\text { coefficient }\end{array}$} \\
\hline & M ean & $\begin{array}{l}\text { Standard } \\
\text { deviation }\end{array}$ & M ean & $\begin{array}{l}\text { Standard } \\
\text { deviation }\end{array}$ & \\
\hline $\mathrm{H}$ ealth & $2 \cdot 83$ & 0.72 & $2 \cdot 77$ & $0 \cdot 70$ & 0.814 \\
\hline M ood & $2 \cdot 11$ & 0.73 & 2.01 & 0.77 & 0.771 \\
\hline Convenience & $2 \cdot 75$ & 0.80 & $2 \cdot 74$ & 0.79 & 0.830 \\
\hline Sensory appeal & 2.99 & 0.63 & 2.94 & 0.65 & 0.729 \\
\hline $\mathrm{N}$ atural content & $2 \cdot 47$ & 0.86 & $2 \cdot 48$ & 0.86 & 0.811 \\
\hline Price & $2 \cdot 83$ & 0.80 & $2 \cdot 79$ & $0 \cdot 79$ & 0.773 \\
\hline Weight control & $2 \cdot 38$ & 0.88 & $2 \cdot 37$ & 0.84 & 0.814 \\
\hline F amiliarity & $1 \cdot 75$ & 0.68 & $1 \cdot 80$ & 0.77 & 0.714 \\
\hline Ethical concern & $1 \cdot 85$ & 0.78 & $1 \cdot 81$ & 0.76 & 0.801 \\
\hline
\end{tabular}

univariate tests indicated significant differences on seven of the nine factors, $F(1,659)=9.92$ to $57 \cdot 9, p<0 \cdot 001$, with only sensory appeal and familiarity not differing between the sexes. F or all the other scales, the ratings for women were significantly 
TABLE 4

A verage ratings on the $\mathrm{F}$ ood $\mathrm{C}$ hoice $\mathrm{Q}$ uestionnaire in men and women. Studies 1 and 2 combined $(n=706)$

\begin{tabular}{|c|c|c|c|c|}
\hline \multirow[t]{2}{*}{ Scale } & \multicolumn{2}{|c|}{ M en } & \multicolumn{2}{|c|}{ Women } \\
\hline & M ean & $\begin{array}{l}\text { Standard } \\
\text { deviation }\end{array}$ & M ean & $\begin{array}{l}\text { Standard } \\
\text { deviation }\end{array}$ \\
\hline $\mathrm{H}$ ealth & $2 \cdot 64$ & 0.77 & 3.01 & 0.62 \\
\hline M ood & $2 \cdot 00$ & 0.73 & $2 \cdot 21$ & 0.74 \\
\hline Convenience & 2.63 & 0.76 & $2 \cdot 87$ & 0.73 \\
\hline Sensory appeal & 2.92 & 0.63 & 3.00 & 0.60 \\
\hline $\mathrm{N}$ atural content & $2 \cdot 27$ & 0.84 & $2 \cdot 64$ & 0.83 \\
\hline Price & $2 \cdot 62$ & 0.82 & $2 \cdot 88$ & 0.75 \\
\hline Weight control & $2 \cdot 01$ & 0.81 & $2 \cdot 60$ & 0.79 \\
\hline Familiarity & 1.79 & 0.71 & $1 \cdot 79$ & 0.71 \\
\hline Ethical concern & $1 \cdot 77$ & 0.74 & $2 \cdot 06$ & 0.76 \\
\hline
\end{tabular}

higher than for men. Effects were particularly prominent for health and weight control, with mean differences of 0.36 and 0.59 respectively.

There were a number of significant correlations between FCQ scales and age. For both women and men, significant positive correlations were found between age and natural content $(r=0.22$ and $0.23, p<0.001)$, familiarity $(r=0.30$ and 0.18 , $p<0.001)$ and ethical concern $(r=0.12$ and $0.20, p<0.025)$. In addition, positive correlations in women were seen between age and health $(r=0.22, p<0.001)$ and sensory appeal $(r=0.18, p<0.001)$ as factors influencing food choice. A mong men, $\operatorname{mood}(r=0.17, p<0.005)$ and weight control $(r=0.25, p<0.001)$ were positively correlated with age. $\mathrm{N}$ either sex showed any association between convenience or price and age. The significance of these effects was unchanged when social desirability was taken into account using partial correlations.

The impact of income on FCQ scales was evaluated in the expectation that people with larger incomes would be less influenced by price in their food choices. The combined samples of Studies 1 and 2 were divided into three income groups: low $(<£ 5000, n=270)$, moderate $(£ 5000-£ 20000, n=228)$ and high $(>£ 20000, n=$ 148). M ultivariate analysis of variance with income as a grouping factor and age, sex and social desirability as covariates produced a significant overall income effect, $F(18,1266)=11.9, p<0 \cdot 0001$. U nivariate analyses indicated that the income groups differed on three factors- price, sensory appeal and familiarity, $F(2,640)=3 \cdot 11$ to $90.4, p<0.05$ (Table 5). A $n$ orderly relationship between income and the importance of price in food selection was apparent, with less emphasis being placed on price by better-off individuals. Familiarity showed the reverse effect, being rated as more important by lower income groups. Sensory appeal was rated as less important by the low-income than either the moderate- or high-income groups.

Tests of Convergent Validity

Scores on the shortened social desirability scale correlated with two of the FCQ scales: health $(r=0.19, p<0.001)$ and natural content $(r=0.16, p<0.001)$. This factor 
A. STEPTOE ET AL.

TABLE 5

$M$ otives for food choice in relation to income

\begin{tabular}{|c|c|c|c|c|c|c|}
\hline \multirow[t]{2}{*}{ Scale } & \multicolumn{2}{|c|}{ Low income } & \multicolumn{2}{|c|}{ M edium income } & \multicolumn{2}{|c|}{$\mathrm{H}$ igh income } \\
\hline & M ean & $\begin{array}{l}\text { Standard } \\
\text { deviation }\end{array}$ & M ean & $\begin{array}{l}\text { Standard } \\
\text { deviation }\end{array}$ & M ean & $\begin{array}{l}\text { Standard } \\
\text { deviation }\end{array}$ \\
\hline $\mathrm{H}$ ealth & $2 \cdot 82$ & 0.73 & $2 \cdot 96$ & 0.67 & $2 \cdot 71$ & 0.73 \\
\hline M ood & $2 \cdot 13$ & 0.75 & $2 \cdot 13$ & 0.72 & 2.02 & 0.72 \\
\hline Convenience & $2 \cdot 78$ & 0.72 & 2.83 & 0.73 & 2.62 & 0.80 \\
\hline Sensory appeal & 2.87 & $0.64^{a}$ & 3.02 & $0.59^{b}$ & 3.01 & $0.58^{b}$ \\
\hline $\mathrm{N}$ atural content & $2 \cdot 35$ & 0.86 & 2.64 & 0.82 & $2 \cdot 42$ & 0.86 \\
\hline Price & $3 \cdot 12$ & $0.70^{a}$ & $2 \cdot 79$ & $0.69^{b}$ & 2.09 & $0.65^{c}$ \\
\hline Weight control & $2 \cdot 30$ & 0.88 & $2 \cdot 42$ & 0.82 & $2 \cdot 27$ & 0.83 \\
\hline F amiliarity & 1.83 & $0 \cdot 70^{\mathrm{a}}$ & 1.79 & $0.68^{b}$ & 1.64 & $0 \cdot 70^{c}$ \\
\hline Ethical concern & 1.91 & 0.78 & 2.04 & 0.76 & 1.79 & 0.72 \\
\hline
\end{tabular}

In each row, cells sharing the same superscript were not significantly different on post hoc tests.

TABLE 6

Value of health and motives for food choice

\begin{tabular}{lccccc}
\hline Scale & \multicolumn{2}{c}{ Low health value } & & \multicolumn{2}{l}{ High health value } \\
\cline { 2 - 3 } \cline { 5 - 6 } \cline { 5 - 6 } & M ean & $\begin{array}{c}\text { Standard } \\
\text { deviation }\end{array}$ & & M ean & $\begin{array}{c}\text { Standard } \\
\text { deviation }\end{array}$ \\
\hline H ealth & 2.72 & 0.71 & & 2.96 & 0.70 \\
M ood & 1.98 & 0.74 & & 2.25 & 0.74 \\
Sensory appeal & 2.86 & 0.63 & & 3.06 & 0.58 \\
N atural content & 2.31 & 0.82 & & 2.61 & 0.86 \\
Weight control & 2.23 & 0.84 & & 2.43 & 0.84 \\
\hline
\end{tabular}

was therefore taken into account when assessing relationships with other measures. In order to test the convergent validity of the scales, a number of a priori predictions were generated concerning associations with other questionnaires.

The Health as a Value measure was administered in both studies, with the expectation that scores would correlate with the FCQ health score. Health value scores averaged 4.46 in women and 4.23 in men, $t=3.17, d f=710, p<0.005$. The associations with FCQ factors were analysed by dividing the population by median split into high and low value of health sub-groups. M ultivariate analysis of variance with health value sub-group and sex as between-subject factors and social desirability as the covariate was then carried out. There was no significant interaction between health value and sex, but a main multivariate effect of health value was observed, $F(9,647)=5 \cdot 27, p<0.005$. U nivariate effects were significant for the $F C Q$ health, mood, sensory appeal, natural content and weight control scales, $F(1,647)=7.81$ to $18.7, p<0.01$ (Table 6). As expected, respondents who place a high value on health had significantly greater scores on the FCQ health scale. However, they also rated mood, sensory appeal, natural content and weight control as more important. The 
value of health was not related to the importance placed on convenience, price, familiarity or ethical factors in determining the choice of food.

Sincepreoccupation with weight control is central to dietary restraint, we predicted that the weight control factor would be correlated with the restraint scale of the DEBQ. R estraint scores were low among men (mean $2 \cdot 19$, SD 0.80 ), so analyses of this factor were confined to women. U sable data were available from 214 of the 220 women in Study 1, and they were divided by median split into those with low (mean $2 \cdot 13$, SD 0.50 ) and high (mean 3.53 , SD 0.51 ) restraint scores. M ultivariate analysis of the FCQ with age and social desirability as covariates showed a significant effect of restraint group overall, $F(9,189)=13.9, p<0 \cdot 001$. U nivariate effects were significant only for two scales. As predicted, FCQ weight control scores were higher in the restrained than unrestrained women, mean $2 \cdot 94$, SD 0.64 vs. 2.12, SD 0.61, F (1, $197)=88.8, p<0 \cdot 001$. In addition, price was considered less significant for high- than for low-restrained women, mean $2 \cdot 72$, SD 0.79 vs. 2.94, SD $0.68, F(1,197)=4.69$, $p<0.05$. FCQ weight control ratings also correlated with $D E B Q$ emotional eating scores among women $(r=0.24, p<0.001)$. It was also found that the FCQ mood scale was positively correlated with both the emotional eating $(r=0.38, p<0.001)$ and external eating scales of the DEBQ.

In relation to locus of control, it was predicted that subjects with high internal MHLOC scores would be more concerned with health and the use of natural ingredients than those with less strong beliefs about personal responsibility for health. These predictions were fulfilled for both women and men with significant correlations between internal LOC scores and F CQ health $(r=0.40$ and $0.29, p<0.001)$ and natural content $(r=0.37$ and $0.16, p<0.05)$. Controlling for social desirability, all correlations in women remained significant, as did the associations between $\mathrm{FCQ}$ health and internal LOC in men. However, the correlation in men between internal $L O C$ and FCQ natural content was no longer significant after social desirability had been taken into account.

$\mathrm{N}$ euroticism as a personality disposition is associated with proneness to anxiety and stress responses. It was therefore predicted that neuroticism might correlate positively with the FCQ mood factor. The association was not significant for women, but was confirmed for men $(r=0.20, p<0.01)$. The openness to experience factor from the NEO was predicted to correlate negatively with familiarity, and this effect was confirmed for both women and men $(r=-0.33$ and -0.25 respectively, $p<0.001)$. These effects remained significant after controlling for social desirability biases.

\section{ISCUSSION}

Our attempt to develop a brief questionnaire to assess perceived influences on food selection at the individual level identified nine distinct factors. Several of the factors are similar to dimensions described by other investigators, including healthfulness, taste or sensory appeal, price, convenience, and tradition or familiarity (D renowski, 1992; L au et al., 1984; R appaport et al., 1992). M ood or affect and concern with weight control have also emerged in previous work (H ollis et al., 1986; Williams et al., 1987). In contrast, some potential influences on food choice, such as how filling or satisfying the food is and how much it is liked by family and friends, did not emerge as consistent factors in these analyses. The F CQ was shown to have high internal consistency in both studies. The confirmatory factor analysis 
suggested that the factors are robust, and adequate short-term stability has also been established.

Since a number of the F CQ scales were intercorrelated, the possibility of a smaller group of higher order factors being useful was explored. A three-factor solution accounted for $58 \%$ of the variance, with the FCQ health, natural content, weight control and ethical concern loading on factor 1 , convenience and price on factor 2 , and mood, sensory appeal and familiarity on factor 3. However, we do not favour this approach for two reasons. Firstly, some individual FCQ scales did not load on single factors: mood and familiarity shared high loading on two or three factors. Secondly, it may be more useful to be able to investigate a wider range of specific motives related to food choice, rather than broad dimensions.

In terms of individual scales, the health factor contains items related to the prevention of chronic disease (e.g. "high in fibre and roughage") and to general nutrition and well-being (e.g. "nutritious"). The preliminary questionnaire administered in Study 1 contained several other items related to nutrition and health (e.g. "easy to digest", "part of a balanced diet") that loaded on the health factor, but less strongly than the six items selected for the final inventory. The health factor also included the item "good for my skin/teeth/hair/nails etc". This is consistent with evidence that concern for appearance may predict healthy dietary choices (H ayes \& R oss, 1987). It is interesting that the item "low in fat" did not load on the health but on the weight control factor. It is possible that the association of dietary fat with weight is a consequence of the sample containing a high proportion of young adults, and that in a middle-aged group more conscious of cardiovascular disease risk, fat restriction would havebeen linked with health and chronic disease prevention. The sex difference in ratings on the health scale indicates that women pay more attention to this factor than do men. The result is consistent with other studies of health-related behaviours and beliefs, which typically show healthier dietary choices and more positive attitudes towards the health benefits of salt and fat restriction and increased fibre intake in women than men (Wardle \& Steptoe, 1991). The importance of health as a reported motive for food choice increased with age in women but not men. Convergent validity for the health scale was provided by the significant and positive associations with health as a value and internal health-related locus of control.

The mood scale contains items related to general alertness and mood, as well as to relaxation and stress control. The emergence of this factor suggests that mood and stress may play a role in determining not only the quantity of food consumed, but also the selection of foodstuffs (Wardle, 1987a). Convergent validity for the mood factor was evaluated by its relationship with the emotional eating and external eating scales of the DEBQ. These effects were seen in women but not men, for whom $D E B Q$ scores were very low, suggesting that there may be sex differences in the relationship between affect-related food selection and dietary disinhibition ( $G$ runberg $\&$ Straub, 1992). A mong men, the mood factor was associated with neuroticism, implying that anxiety-prone individuals may be more likely to be influenced by the desire to maintain emotional well-being through eating than are emotionally more stable men.

The convenience factor includes items related both to the purchase and preparation of food, while sensory appeal involves smell, taste and appearance. R appaport et al. (1992) found that health motives were negatively correlated with convenience, while health and pleasure (sensory appeal) were unrelated. $N$ either finding was confirmed 
in this analysis, since health was not significantly associated with convenience, while health and sensory appeal showed a small but reliable positive correlation (Table 2). The discrepancy with earlier findings may have resulted from the very different measurement methods employed. In the comparison of income groups, the low income group rated sensory appeal as less important than did better off subjects. People with less disposable income may not be able to take taste into consideration as much as wealthier individuals, and may have to set other priorities.

The natural content scale reflected concern with the use of additives and the selection of natural ingredients. The correlation between the health and natural content factors was high $(r=0.59$ in Study 1 and $r=0.63$ in Study 2), suggesting a strong association between the two. $\mathrm{N}$ evertheless, it would appear that general health-promoting aspects of nutrition are perceived as distinct from concerns related to toxins and the ingestion of unnatural "non-foods" added for cosmetic reasons. It can be argued that additives and artificial ingredients are frequently incorporated into foods as preservatives, and may thereforehave beneficial properties in preventing consumption of foods that have decayed. It would be interesting therefore to discover whether respondents in cultures with a less jaundiced opinion of the food industry would view natural ingredients and the absence of additives so positively.

Price is an obvious influence on food choice. The cost of food is a much more important element in selection among people with low incomes compared with those that are better off (Table 5). Price was also rated as more important among women than men. In the U.K., women typically have responsibility for food shopping for the household, so may be more aware of budgetary limitations than are men with their more spontaneous pattern of food purchases. A nother interesting observation is that women showing dietary restraint were less influenced by price than the unrestrained. It may be that desire to eat low calorie food outweighs considerations of cost for restrained eaters.

It was anticipated that weight control would emerge as a significant factor in food choice in the light of the extensive research on dietary restraint and the prevalent cultural preference for thin bodies. A significant association was observed between weight control and mood as factors influencing food choice, and this is consistent with previous research (Wardle et al., 1992). The correlation of weight control with natural content $(r=0.31$ in Study 1 and $r=0.42$ in Study 2) reflects the fact that many people practising caloric restriction favour natural foods such as raw vegetables over prepared dishes. As predicted, scores on the FCQ weight control scale were higher in restrained than unrestrained women. They were unrelated to income, but were higher among respondents who stated that they valued health highly.

The eighth factor to emerge in the factor analysis was labelled familiarity. It included items concerning how important it is for the person to eat their accustomed diet, rather than being adventurous in food choices. A positive association between familiarity and mood was observed, suggesting that people whose dietary selection is influenced by the need to regulate stress responses also prefer familiar foods. Familiarity was one of the few factors not to differ on average between men and women. It was, however, related to age, since it appears that older people are less adventurous in their choices. A ssociations were also observed between familiarity and income, with significantly higher familiarity ratings among people with lower incomes. It may be that as incomes increase, people are less bound to buy only food they know about, and can afford to take greater risks with food selection. For the financially less well off, the consequences of an unfortunate choice are more severe, 
and people will be more likely to select what they know they like. Corroborative evidence concerning the familiarity scale is provided by the negative correlations with the openness to experience factor on the N E O F ive-F actor Personality Inventory. $\mathrm{H}$ igh scores on this personality factor are thought to reflect openness to new experiences and broad interests, and might therefore be relevant to adventurousness in food choice.

E thical concern emerged as an independent factor influencing food choice. I tems related to environmental and political issues loaded on this factor. It is notable that ethical concern was not correlated with social desirability scores at a statistically acceptable level, so endorsing the ethical concern items was not simply a reflection of presenting a set of motives that was presumed to be socially acceptable. In the present sample, ratings of ethical concern increased with age, and were higher among women than men. This suggests that the male students who constituted the majority of the younger men in the study population were particularly unaffected by ethical issues in relation to food choice.

Sensory appeal, health, convenience and price are the most important factors on average (Table 4), with the five other factors being typically endorsed less strongly. $\mathrm{H}$ ealth is certainly not more important than other factors on average, and this supports the argument that a multidimensional approach to motives governing food choice is appropriate. The variation in the relative importance of different factors for different segments of the population may make it possible to create profiles for distinct groups. For example, price was the most important factor for the lowest income group, and sensory appeal for the better off (Table 5). A ppropriate strategies for health promotion may perhaps be developed for sectors with different priorities. If, for instance, convenience takes precedence over health, then education and information about healthy food that is also readily available and easy to prepare might be of greater value than messages emphasizing health alone.

The limitations of this study must be recognized. $D$ ata were only available from the segment of the sample who returned the questionnaire, so may represent the views of individuals with an interest in food selection. The questionnaire is concerned with the factors that are perceived as relevant to food choice, and these factors do not necessarily reflect actual dietary selection behaviour. The cultural limitations of this approach to the investigation of food choice should also be recognized. The nine factors that emerged in this study were endorsed by members of a society in which a wide range of safe products are readily available and well labelled. A wareness of environmental issues is relatively high, and a substantial proportion of food is imported so issues such as country of origin are salient. Consumers are not restrained by actual shortages, or by seasonal variations to the extent that might be the case in rural, less affluent or less developed societies. Different factors might assume greater importance in other cultures, in societies that produce most of their own food, or in populations exposed to an unpredictable food supply. Nevertheless, within western urban populations, the FCQ provides the opportunity to assess a broad range of factors perceived as relevant to food selection.

\section{R EFERENCES}

Bell, A. C., Stuart, A. M ., R adford, A. J . \& Cairney, P. T. (1981) A method for describing food beliefs which may predict personal food choice. J ournal of $\mathrm{N}$ utrition Education, 13, 22-26. 
Bentler, P. M. (1989) EQS: Structural Equations Program M anual. Los A ngeles: BMDP Statistical Software Inc.

Bentler, P. M . (1990) Comparative fit indexes in structural models. Psychological Bulletin, 107, 238-246.

Bentler, P. M . \& Bonett, D . G . (1980) Significance tests and goodness of fit in the analysis of covariance structures. P sychological Bulletin, 88, 588-606.

Cannon, G. (1992) Food and H ealth: The Experts A gree. London: Consumers' A ssociation.

Cockerham, W. C., K unz, G.\& Lueschen, G. (1988) On concern with appearance, health beliefs, and eating habits: a reappraisal comparing A mericans and West $G$ ermans. J ournal of $\mathrm{H}$ ealth and Social Behavior, 29, 265-270.

Costa, P. T. \& M cCrae, R. R. (1991) NEO PI-R Professional M anual. Odessa, U.S.A.: Psychological A ssessment R esources Inc.

Costa, P. T. \& M cCrae, R. R. (1992) Bibliography for the R evised NE O Personality Inventory and NEO Five-Factor Inventory. Odessa, U.S.A.: Psychological A ssessment Resources Inc.

D renowski, A. (1992) N utritional perspectives on biobehavioral models of dietary change. In: K. K. DeR oos (Ed.), P romoting D ietary Change in Communities. Pp. 96-112. Washington: $\mathrm{F}$ red $\mathrm{H}$ utchinson $\mathrm{Cancer} \mathrm{R}$ esearch $\mathrm{C}$ enter.

Fine, B. \& Leopold, E. (1993) The World of C onsumption. L ondon: R outledge.

Glanz, K., K ristal, A., Sorensen, G., Palombo, R., H eimendinger, J. \& Probart, C. (1993) Development and validation of measures of psychosocial factors influencing fat- and fibre-related dietary behavior. P reventive M edicine, 22, 373-387.

Grunberg, N. E. \& Straub, R. O. (1992) The role of gender and taste class in the effects of stress on eating. Health P sychology, 11, 97-100.

H armatz, M . G . \& K err, B. B. (1981) Over-eating behaviour: a multi-causal approach. O besity and $M$ etabolism, 1, 134-139.

H ayes, D.\& R oss, C. E. (1987) Concern with appearance, health beliefs, and eating habits. J ournal of $\mathrm{H}$ ealth and Social Behavior, 28, 120-130.

H ealthy P eople 2000 (1992) Boston: J ones and Bartlett.

Hollis, J. F., Carmody, T. P., Connor, S. L., Fey, S. G. \& M atarazzo, J. D. (1986) The $\mathrm{N}$ utrition A ttitudes Survey: associations with dietary habits, psychological and physical well-being, and coronary risk factors. H ealth P sychology, 5, 359-374.

K ristal, A. R., Bowen, D. J., Curry, S. J., Shattuck, A. L.\& H enry, H. J . (1990) N utrition knowledge, attitudes, and perceived norms as correlates of selecting low-fat diets. $\mathrm{H}$ ealth E ducation and R esearch, 5, 467-477.

K rondl, L. \& Lau, D. (1982) Social determinants in human food selection. In: L. Barker (Ed.), The Psychobiology of Human Food Selection. Pp. 139-151. Chichester: Ellis Horwood.

L ands, W. E. N ., H amazaki, T., Yamazaki, K ., Okuyama, H ., Sakai, K ., G oto, Y.\& H ubbard, V. S. (1990) Changing dietary patterns. A merican J ournal of Clinical Nutrition, 51, 991-993.

L au, D ., K rondl, M . \& Coleman, P. (1984) Psychological factors affecting food selection. In: J. Galler (Ed.), N utrition and B ehavior. Pp. 397-415. N ew York: Plenum Press.

L au, R. R., Hartman, K. A. \& Ware, J. E. (1986) Health as a value: methodological and theoretical considerations. $H$ ealth $P$ sychology, 5, 25-43.

M cCann, B., Warnick, G. \& K nopp, R. (1990) Changes in plasma lipids and dietary intake accompanying shifts in perceived workload and stress. Psychosomatic M edicine, 52, 97-108.

M cCann, B. S., R etzlaff, B. M., Dowdy, A. A., Walden, C. E. \& K nopp, R. H. (1990) Promoting adherence to low-fat low-cholesterol diets: review and recommendations. J ournal of the A merican Dietetic Association, 90, 1408-1414.

M arsh, H. W., Balla, J. R . \& M cD onald, R . P. (1988) G oodness-of-fit indices in confirmatory factor analyses: the effects of sample size. P sychological Bulletin, 103, 391-410.

M ichela, J . \& Contento, I. (1986) Cognitive, motivational, social and environmental influences on children's food choices. H ealth P sychology, 5, 209-230.

Parraga, I. M . (1990) D eterminants of food consumption. J ournal of the A merican Dietetic A ssociation, 90, 661-663.

Polivy, J., H erman, P. C. \& Warsh, S. (1978) Internal and external components of emotionality in restrained and unrestrained eaters. J ournal of A bnormal P sychology, 87, 497-504. 
R appaport, L., Peters, G., Huff-Corzine, L. \& Downey, R. (1992) Reasons for eating: an exploratory cognitive analysis. E cology of Food and N utrition, 28, 171-189.

R ozin, P. (1984) The acquisition of food habits and preferences. In: J. D. M atarazzo et al. (Eds), Behavioral $\mathrm{H}$ ealth: $\mathrm{A} \mathrm{H}$ andbook of $\mathrm{H}$ ealth $\mathrm{Enhancement}$ and $\mathrm{D}$ isease $\mathrm{P}$ revention. Pp. 590-607. N ew York: Wiley-Interscience.

The $\mathrm{H}$ ealth of the $\mathrm{N}$ ation (1992) L ondon: H M SO.

Sanjur, D. (Ed.) (1982) Social and C ultural Perspectives of N utrition. Englewood Cliffs: Prentice $\mathrm{H}$ all.

Smith, A. M . \& Owen, N . (1992) A ssociations of social status and health-related beliefs with dietary fat and fibre densities. P reventive M edicine, 21, 735-745.

Strahan, R.\& G erbasi, K. C. (1972) Short, homogenous versions of the M arlowe-Crowne social desirability scale. J ournal of Clinical P sychology, 28, 191-193.

Stunkard, A . J . \& M essick, S. (1985) The three factor eating questionnaire to measure dietary restraint, disinhibition and hunger. J ournal of $P$ sychosomatic R esearch, 29, 71-84.

Trenkner, L. L., R ooney, B., Viswanath, K., Baxter, J., Elmer, P., Finnegan, J. R ., Graves, K., Hertog, J., M ullis, R., Pirie, P. \& Potter, J. (1990) Development of a scale using nutrition attitudes for audience segmentation. $\mathrm{H}$ ealth $\mathrm{E}$ ducation Research, 5, 479-487.

Trichopoulou, A. D. \& Efstathiadis, P. P. (1989) Changes of nutrition patterns and health indicators at the population level in G reece. A merican J ournal of Clinical N utrition, 49, 1042-1047.

Tuorila, H.\& Pangborn, R. M . (1988) Prediction of reported consumption of selected fatcontaining foods. A ppetite, 11, 81-95.

Van Strien, T., Fritjers, J. E. R., Bergers, G. P. A. \& D efares, P. B. (1986) D utch eating behaviour questionnaire for assessment of restrained, emotional and external eating behaviour. International J ournal of Eating Disorders, 5, 295-315.

Wallston, D. S., Wallston, K . A . \& D eVellis, R . (1978) D evelopment of the multidimensional health locus of control (M H L C) scales. H ealth Education M onographs, 6, 160-170.

Wardle, J. (1986) The assessment of restrained eating. Behaviour Research and Therapy, 24, 213-215

Wardle, J. (1987a) Compulsive eating and dietary restraint. B ritish J ournal of Clinical Psychology, 26, 47-55.

Wardle, J. (1987b) E ating style: a validation study of the D utch E ating B ehaviour Q uestionnaire in normal subjects and women with eating disorders. J ournal of P sychosomatic R esearch, 31, 161-169.

Wardle, J. (1993) Food choices and health evaluation. Psychology and $\mathrm{H}$ ealth, 8, 65-75.

Wardle, J. \& Steptoe, A. (1991) The European Health and Behaviour Survey: rationale, methods and results from the $U$ nited $K$ ingdom. Social Science and $M$ edicine, 33, 925-936.

Wardle, J., M arsland, L., Sheikh, Y., Quinn, M ., F edoroff, I. \& Ogden, J. (1992) E ating style and eating behaviour in adolescents. A ppetite, 18, 167-183.

Williams, A., Spencer, C. P. \& Edelman, R. J. (1987) R estraint theory, locus of control and the situational analysis of binge eating. Personality and Individual Differences, 8, 67-74.

Received 22 D ecember 1994, revision 15 February 1995 